\title{
Creer y no creer: modalidad apelativa y aserción en el lenguaje
}

To believe and not to believe: appellative modality and assertion in language

\author{
Francisco Javier Grande Alija \\ Universidad de León, Departamento de Filología Hispánica y Clásica, León, España. \\ Correo electrónico: fjgraa@unileon.es
}

\begin{abstract}
Basándonos principalmente en datos suministrados por el CREA (Corpus de Referencia del Español Actual), describimos los usos “metadiscursivos” de los imperativos créeme y no creas. A partir del análisis de estos usos, consideramos las relaciones semánticas y funcionales que se observan entre ellos así como las transformaciones formales y semánticas que se detectan en algunos casos. Propiedades como la fijación formal, idiomaticidad, carácter extrapredicativo,... propician una reflexión sobre las relaciones que, en el plano del discurso, se dan entre los procedimientos léxicos y aquellos que se adscriben a la categoría de los marcadores del discurso. El análisis de créeme y no creas muestra que el paso entre estos dos polos es gradual y que, junto a usos que se acercan al prototipo de los marcadores, hay otros que solo de manera tangencial se adscriben a esa categoría funcional.
\end{abstract}

Palabras clave: modalidad apelativa, aserción, fórmulas léxicas, marcador del discurso, categorización no discreta.

The present study is based on empirical data extracted from the CREA corpus (Corpus de Referencia del Español Actual). The aim is to describe the metadiscursive uses of two imperative forms -créeme and no creas-. These communicative uses are analyzed, and the semantic and functional relationships established between the two, as well as the formal and semantic changes observed in some cases, are studied in detail. Properties such as the formal fixedness, idiomaticity, extra-predicative character, etc. prompt an analysis of the relationships (on the dimension of discourse) between lexical processes and those processes ascribed to the category of discourse markers. The analysis of créeme and no creas illustrates that the difference between these two extremes is gradual. Some uses are close to the prototypical use of discourse markers, whereas others are only marginally similar to that functional category.

Key words: appellative modality, assertion, lexical formulae, discourse marker, nondiscrete categorization. 


\section{INTRODUCCIÓN}

Nos ocupamos en este trabajo -desde los planteamientos de la Pragmática y el Análisis del Discurso- del estudio de ciertos valores metadiscursivos, es decir, orientados hacia el propio acto de discurso, que presentan las formas apelativas créeme y no creas, las cuales se caracterizan por combinar dos dimensiones: una asertórica (incorporan una representación del mundo) y una apelativa (se trata de influir sobre el oyente). Nos marcamos los siguientes objetivos: 1) Describir y analizar su comportamiento formal, semántico y discursivo, a fin de considerar el modo en que contribuyen a la gestión de los contenidos asertivos que se expresan en un enunciado; 2) proponer una reflexión sobre el hecho de que, en la organización del discurso, el paso entre los procedimientos léxicos y los basados en la "gramática" es gradual.

\section{ModAlidAd APELATIVA Y ASERCIÓN: LA SIMBIOSIS EPISTÉMICO-APELATIVA DE CRÉEME Y NO CREAS ${ }^{1}$}

Nos interesa analizar el comportamiento discursivo de ejemplos como los siguientes: 1) Te estás equivocando, créeme, 2) Créeme que te estás equivocando, 3) Te estás equivocando, no creas y 4) No creas que te estás equivocando. Dejando por el momento a un lado las diferencias que presentan, ahora queremos llamar la atención sobre los rasgos que tienen en común. Con independencia de cuál sea el modo de inserción del predicado asertivo en la estructura sintagmática, en todos los casos aparece la misma organización conceptual: junto a un componente de naturaleza proposicional, que incorpora una representación del mundo (dictum), se tiene un comentario acerca de ese componente descriptivo (modus). Se entra así en el dominio de la categoría semántica de la modalidad.

Como consecuencia de sus características léxicas y gramaticales, en estos usos de creer se imbrican dos niveles modales: en primer lugar, el que, al reflejar la fuerza del compromiso de cierta persona con respecto a lo que dice, pertenece al ámbito de la modalidad epistémica y, en concreto, al de la aserción; en segundo lugar, el que, al estar orientado hacia la propia enunciación, fija el carácter apelativo de la misma.

La anterior organización modal deja traslucir varias posturas:

- El oyente está convencido de la verdad de cierta proposición.

- El hablante considera que esa proposición representa un hecho falso.

- En virtud del desajuste entre lo defendido por el oyente y lo planteado por el hablante, este último trata de influir sobre aquel para que modifique sus creencias.

Como indicios que nos permiten fijar la postura de cada uno de los interlocutores tenemos: en los usos parentéticos, la naturaleza del enunciado “dictal” (enunciado declarativo en modo indicativo); en los otros usos, la presencia del modo indicativo en la oración sustantiva. Estos indicios se limitan a manifestar que alguien -que,

Para llevar a cabo nuestro análisis, nos hemos apoyado principalmente en ejemplos tomados del Corpus de Referencia del Español Actual (CREA) de la Real Academia Española (http://www.rae.es). Hemos completado la muestra con ejemplos tomados de internet y con otros sacados del corpus de conversación coloquial del grupo Val.Es.Co (Briz coord. 1995) y de diversas obras literarias que se citan al final. Por último, se ha incorporado también un número muy reducido de ejemplos de creación propia (aquellos que no tienen ninguna indicación sobre su procedencia). 
según los usos, puede ser el hablante o el oyente- acepta como verdadero el contenido representado por la oración sustantiva o el enunciado dictal. El contexto de polémica y refutación nos permite deducir pragmáticamente que el otro participante defiende justamente lo contrario.

Otro indicio es el propio verbo de creencia. Ciertamente, su función principal es señalar el intento del hablante de influir sobre las creencias del oyente. Sin embargo, también nos permite concretar a quién se deben asignar las modalizaciones epistémicas asociadas al indicativo y a la modalidad declarativa. Por ejemplo, en el caso de créeme corresponden necesariamente al hablante, de donde deducimos que el oyente mantiene lo contrario. En todo esto parece intervenir una lógica conversacional que no permite defender de forma simultánea una proposición y su contraria: no puedo pedir, sugerir, proponer... a alguien que crea algo y, al mismo tiempo, implicar que yo no lo creo.

Teniendo en cuenta estos indicios, podemos establecer el siguiente reparto de responsabilidades con respecto a la verdad de las proposiciones involucradas:

Tabla 1.

\begin{tabular}{|l|c|c|}
\hline & Creencias del hablante & Creencias del oyente \\
\hline Te estás equivocando, créeme & $\mathrm{p}$ & no $\mathrm{p}$ \\
\hline Créeme que te estás equivocando & $\mathrm{p}$ & no $\mathrm{p}$ \\
\hline Te estás equivocando, no creas & $\mathrm{p}$ & no $\mathrm{p}$ \\
\hline No creas que te estás equivocando & no $\mathrm{p}$ & $\mathrm{p}$ \\
\hline
\end{tabular}

Por último, estos usos del verbo creer se encuentran ligados al aquí y el ahora del presente de enunciación. Tienen, por así decirlo, una dimensión indicial y deíctica que implica una mirada interna al propio acto de enunciación en el que se integran. Presentan una orientación metadiscursiva. Con ello queremos decir que las evaluaciones epistémicas que se expresan apuntan a las bases cognitivas en las que se apoya el acto de habla en que aparecen. No se trata de modificar las creencias del destinatario en un futuro más o menos próximo, como en A partir de ahora, créeme o ya nunca más te volveré a decir nada, sino de implicar que lo que se dice es verdadero o falso para el locutor a la vez que se intenta que el destinatario lo vea también de esa manera.

\section{CRÉEME DE ORIENTACIÓN METADISCURSIVA}

\subsection{La contribución de créeme a la aserción}

Un enunciado de modalidad declarativa sin ningún tipo de cualificación modal explícita, y salvo que contextualmente haya algún tipo de indicio que sugiera lo contrario (como, por ejemplo, cuando hablamos irónicamente), parece representar el mayor grado de compromiso epistémico del hablante con la verdad de lo que comunica.

La inclusión del verbo creer utilizado apelativamente y con una orientación metadiscursiva no implica cambio alguno en la valoración epistémica del hablante: He hecho todo lo humanamente posible $=$ Créeme, he hecho todo lo humanamente 
posible $=$ Créeme que he hecho todo lo humanamente posible. En los tres casos está convencido de la verdad de la proposición "he hecho todo lo humanamente posible".

Si nos centramos ahora en el oyente, la aparición de créeme ¿supone algún cambio en lo que se espera de él? Para entender su contribución, necesitamos tomar como referencia un enunciado declarativo sin marcador modal explícito como, por ejemplo, He hecho todo lo humanamente posible ¿Qué ocurre desde la perspectiva de la persona a la que se dirige ese enunciado? ¿Lo emite el hablante con la intención de convencerla de la verdad de lo que dice? En realidad, esto ocurre solo en ciertas ocasiones y, en concreto, cuando se maneja una concepción "fuerte" de la aserción, es decir, cuando se entiende como un acto de habla por el que el hablante aporta al interlocutor una información nueva que considera verdadera para que este último, a su vez, la acepte como tal. Sin embargo, esta no es más que una entre las múltiples posibilidades de uso de los enunciados declarativos de carácter asertivo. Lo fundamental es que el hablante asume la verdad de lo que dice y considera que es suficientemente relevante como para tenerse en cuenta. Ahora bien, ¿con qué intención concreta manifiesta la verdad de ese hecho? Esto solo se puede establecer por referencia a un contexto particular².

Por otra parte, convencer al interlocutor es un efecto perlocutivo: se trata de determinar cómo nuestras palabras influyen sobre los demás. Sin embargo, los efectos perlocutivos no solo dependen de la naturaleza comunicativa de nuestras palabras, sino también de otros muchos factores particulares asociados al interlocutor y a sus circunstancias personales, de modo que por mucho que alguien pretenda convencer a su interlocutor de la verdad de lo que le dice, no hay ninguna garantía de que lo consiga. El influir sobre las creencias del interlocutor y lograr convencerlo de que se le comunica la representación de un hecho verdadero puede ser un efecto perlocutivo deseado y buscado en muchas enunciaciones declarativas de carácter asertivo. Sin embargo, no es el único, ni es imprescindible. Como consecuencia de ello, en modo alguno puede aparecer marcado en la estructura semántica de este tipo de enunciaciones declarativas. Es algo que solo se puede establecer indicialmente, es decir, por medio de la comunicación ostensivo-inferencial (Sperber y Wilson 1994).

En conclusión, al comparar He hecho todo lo humanamente posible y Créeme, he hecho todo lo humanamente posible se observa que no pueden considerarse desde la perspectiva de la intencionalidad comunicativa como equivalentes. En el ejemplo con el verbo de creencia, el hablante manifiesta de forma inequívoca su intención de influir sobre las creencias del interlocutor para convencerlo de la verdad de lo que le dice. Como tal, apela a su condición de enunciador válido y fiable cuya opinión merece tenerse en cuenta. En otras palabras, enfatiza, explicita y destaca lo que en otras enunciaciones asertivas solo puede fijarse implícita e indicialmente, y no siempre.

\subsection{Propiedades formales y semánticas de créeme usado metadiscursivamente}

Cuando el verbo de creencia aparece en construcción parentética, puede usarse antes o después del enunciado sobre el que se actúa de forma global:

\footnotetext{
En esta explicación se está contraponiendo la concepción semántica de la aserción (el hablante se limita a proponer como verdadero cierto contenido proposicional) a una concepción pragmática (se trata de dilucidar el acto de habla concreto que realiza el hablante al utilizar un enunciado que representa un estado de cosas que se estima verdadero). Según esto, nada impide que una aserción semántica acabe culminando en la realización de actos de habla tan dispares como una invitación, una orden, una amenaza, un aviso... Véase Confais (1990) y Grande Alija (2002).
} 
(1) - Me tengo que callar cosas que probablemente me hubieran permitido librarme de la cárcel, pero aquí estoy -dijo-. Yo no me quedé con los 300 millones de los que se me acusa, te lo aseguro. Y estoy callado... Podría hacer mucho daño, créeme, Julián -dijo (E. Ekaizer, Vendetta, CREA).

(2) [Ana opina que ciertas películas son estúpidas] Lili.- ¿Estúpidas?

Ana.- Y dañinas. Hacen mucho daño; créeme, hija, mucho daño; tendrían que estar prohibidas, sobre todo para la gente joven como tú (E. Caballero, Quinteto de Calcuta, CREA).

Sin embargo, no hay que descartar que el comentario parentético incida sobre un único sintagma, en concreto aquel que transmite una información que, desde el punto de vista del interlocutor, puede resultar más dudosa y cuestionable:

(3) [el autor ofrece una lista de elogios muy retóricos y exagerados dirigidos a un personaje paródico: Rodolfo Chikilicuatre] Cantamos estos títulos con la emoción del chambelán al introducir ante el emperador de Bizancio a Teodoro Comneno, señor de Adrianópolis, duque de Tracia, déspota de Epiro. Y escribimos, créasenos, con la mayor seriedad estas notas en honor de quien ha de representar a España en Eurovisión (Valcárcel 2008:11). Se quiere poner de relieve que se está hablando "con la mayor seriedad” a pesar de que hay claros indicios de que se está hablando en broma.

(4) En cambio, cuando el predicado epistémico introduce una oración sustantiva que aporta el contenido

representativo siempre afecta al conjunto de la misma:

(5) "Después venían, pero por casualidad, tres mujeres sensacionales: Elizabeth Oria, Lila Díaz y Alejandra González. Pónganlas en el artículo, por favor”.

- Si no, puede parecer que hay un sesgo medio machista.

- Pero créeme que fue absoluta coincidencia. A mí esas tres mujeres me gustaron mucho. Incluso, en algunos poemas eran de una libertad y una fuerza iguales o superiores a los que ganaron (Revista Hoy, 15-21/12/1997, CREA).

En este otro ejemplo encontramos seguidos los dos tipos de construcción:

(6) - Bueno... Pero tú cuéntame ahora cómo te sientes, que es lo más importante de todo. - Por fuera, ya lo ves. Debo de seguir tan hinchado como ayer, al salir de la clínica, pero eso es natural y sólo cuestión de paciencia y de esperar que me quiten los puntos. Además, no me preocupa nada, créeme, amor. Y créeme también que lo único realmente importante es que hayamos despertado juntos y que sea verdad [...] (A. Bryce Echenique, El huerto de mi amada, CREA).

Estas dos muestras de créeme cumplen, en el plano semántico, la misma función. Sin embargo, se aprecia una diferencia: mientras que el primero puede admitir tanto la construcción parentética como la variante con oración sustantiva, el segundo solo acepta la última alternativa. La causa de este comportamiento se encuentra en la presencia del adverbio también. Este último dato nos pone sobre la pista de algo importante: el créeme parentético se comporta como una especie de isla en el seno de la estructura sintagmática. Aparte de ir separado por pausas, no admite la presencia de ningún tipo de modificador, complemento o argumento, salvo el representado por 
el pronombre átono $m e^{3}$. En cambio, la otra variante, aparte de llevar asociada una oración sustantiva y un pronombre átono en función de complemento indirecto, puede combinarse con ciertos conectores ( $y$, pues, entonces, pero...) y formas adverbiales como también, incluso y sobre todo, lo cual indica una mayor integración en la estructura sintagmática del enunciado. No obstante, parece reacia a la presencia de un complemento circunstancial, aunque admite mejor la de un circunstante: ?Pero ahora créeme que fue absoluta coincidencia / Pero créeme, aquí y ahora, que fue absoluta coincidencia.

Pensamos que este comportamiento es síntoma de un proceso de transformación todavía en ciernes, para nada cerrado ni culminado 4 . La forma apelativa créeme, sobre todo en el caso de la variante parentética, muestra una clara tendencia a actuar como una especie de operador que repercute sobre el conjunto de la proposición y con el que el hablante intenta mejorar la eficacia perlocutiva del propio acto de habla en que está integrado. En ello ha debido de resultar decisiva la orientación metadiscursiva y deíctica que asume esta forma apelativa en los usos analizados, lo cual significa que mira hacia el propio acto de habla en curso y a las condiciones modales e interactivas en que se desarrolla. Al estar ligada al aquí y al ahora de la enunciación, queda bloqueada, o al menos se complica, la posibilidad de introducir cualquier tipo de precisión sobre las circunstancias en que se desarrolla tal influencia ${ }^{5}$.

\subsection{Condiciones de uso de créeme metadiscursivo}

Como ya se ha visto, al utilizar estas formas el hablante no se limita a presentar una información como verdadera, se muestra además como un hablante fiable y sincero y, por ello, en condiciones de solicitar la aquiescencia del interlocutor. ¿Cuándo el hablante se ve abocado a tener que insistir, mediante el uso de créeme, en esto? Pensamos que esta situación se da especialmente cuando en el discurso está presente una información que, de alguna manera, es contraria a lo que defiende el hablante y que, sin embargo, el oyente podría dar por válida. Dicho de otra forma, el uso de créeme se enmarca en un contexto de naturaleza polémica en el que se enfrentan dos puntos de vista: el mantenido por el hablante y el que podría aceptar el oyente.

Ciertamente, es factible, aunque nosotros no hemos encontrado ningún ejemplo real, un diálogo en que créeme aparezca en el marco de la unidad conversacional del intercambio ${ }^{6}$ (-A: $p$, $-\mathrm{B}$ : Créeme, no $p$ ). Sin embargo, lo normal es que todo sea más sutil, es decir, que nos movamos en el terreno de lo implícito: se cuestionan contenidos que de alguna forma están sugeridos o se podrían deducir del discurso precedente.

En ocasiones, tales contenidos implícitos forman parte del contexto previo:

Hay que reconocer que se pueden incluir otros pronombres átonos (créemelo, créetelo...).

Insistiremos sobre esta cuestión en el apartado 5.5 .

Como propiedades exclusivas de la variante parentética tendríamos: carácter extrapredicativo, movilidad e independencia sintáctica y entonativa.

$6 \quad$ El intercambio es una unidad estructural de la conversación que pertenece al nivel dialógico: "Dos intervenciones sucesivas de distintos emisores, una de inicio y otra de reacción” (Briz y Grupo Val.Es.Co 2003: 28). El par adyacente de pregunta-respuesta sería un ejemplo prototípico de intercambio. 
(7) - Como me hayas mentido y lo encontremos en esta casa, te juro que le rompo las dos piernas a tu padre - susurró Fumero.

- Mi padre no sabe nada. Déjele en paz.

- Tú sí que no sabes ni a lo que juegas. Pero en cuanto trinque a tu amigo, se acabó el juego. Ni jueces, ni hospitales, ni hostias. Esta vez me voy a encargar personalmente de sacarle de la circulación. Y voy a disfrutar haciéndolo, créeme [...] (C. Ruiz Zafón, La sombra del viento, CREA).

No es esperable en un policía (Fumero), es decir, un representante de la ley, el comportamiento al que se hace referencia en el texto y que además disfrute haciéndolo.

En otros casos, los contenidos implícitos que se cuestionan son más bien implicaturas, es decir, deducciones pragmáticas que se podrían derivar de las palabras dichas por el interlocutor en un determinado contexto. Interviene un proceso inferencial -con premisas y conclusiones - cuya responsabilidad se atribuye al oyente:

(8) - Yo no sé lo que es tener padres, me los quitaron tan pronto que no tuve tiempo ni de discutir con ellos. En cambio tú has disfrutado de tu madre, has estado con ella hasta el final.

- Pero le importé muy poco. Es ahora cuando me entero de dónde se metía.

- Si le importaras tan poco no habría tirado la vida por ti. Siempre te tuvo presente, créeme (M. Longares, Romanticismo, CREA).

La afirmación que acompaña a créeme (Siempre te tuvo presente) refuta una de las posibles implicaturas que se podrían derivar de lo que afirma el interlocutor en la intervención previa (Pero le importé muy poco $\rightarrow$ "nunca me tuvo presente").

Teniendo en cuenta esto, no es de extrañar que créeme se acomode perfectamente a la aparición de una negación polémica7:

(9) [Hablan de una estilográfica que están viendo en un escaparate]

- Haremos una cosa -propuso-. Cuando ya tengas edad de empezar a escribir, volvemos y la compramos.

- ¿Y si se la llevan antes?

- Ésta no se la lleva nadie, créeme. Y si no, le pedimos a don Federico que nos haga una, que ese hombre tiene las manos de oro (C. Ruiz Zafón, La sombra del viento, CREA).

El enunciado negativo sobre el que incide créeme refuta un contenido implícito que se podría deducir a partir de la intervención interrogativa previa ( $\mathrm{Y}$ si se la llevan antes? $\rightarrow$ "alguien se la puede llevar antes").

Por la misma razón, créeme aparece frecuentemente en estructuras contraargumentativas. Si nos atenemos a la caracterización de Ducrot (1990), tales estructuras implican un evidente componente polémico y refutativo (se rechazan ciertas conclusiones presentes de algún modo en el discurso y, por el contrario, se validan otras). Como es de esperar, créeme aparecerá asociado al miembro de la estructura que implica una mayor fuerza argumentativa y que, en consecuencia, determina la continuación del discurso:

Según O. Ducrot (1986), en el caso de la negación polémica, se utiliza un enunciado negativo porque en el contexto en el que se produce el acto de discurso parece prevalecer la información contraria, que es precisamente la que el locutor desea rechazar. 
(10) [Una mujer sugiere no utilizar ningún anticonceptivo]

- No te preocupes, me cuidaré yo.

- Pero estos días no hay peligro, créeme. Está por venirme la regla (J. Bayly, La mujer de mi hermano, CREA).

(11) - Qué asco, mi amor, la verdad. Me parte el alma dejarte, aunque sea por un par de semanitas, pero créeme que lo que más me desespera es dejarte con ese par de seres tan vomitivos (A. Bryce Echenique, El huerto de mi amada, CREA).

\section{USOS METADISCURSIVOS DE NO CREAS}

En los siguientes apartados nos ocupamos de estos usos de no creas:

- En discursos monológicos y en discursos dialógicos (en el nivel de la unidad conversacional de la intervención ${ }^{8}$ ), no creas introduce una oración sustantiva (No creas que es bueno) o aparece en construcción parentética (Es bueno, no creas).

- En discursos dialógicos, pero esta vez en el marco de la unidad del intercambio, no creas introduce una intervención reactiva con la que el hablante responde a una intervención anterior del interlocutor: -A: Es bueno, -B: No creas.

\subsection{No creas que... como marca de la orientación polémica del discurso}

\subsubsection{La dependencia contextual de la negación}

Como es de sobra conocido, la presencia de la negación resulta muy marcada: los enunciados negativos son mucho menos informativos que los afirmativos, de modo que si el hablante ha decidido utilizar la negación es porque tiene buenas razones para hacerlo. En el caso que nos ocupa, la negación está señalando la dependencia que el discurso actual del hablante mantiene con respecto a un contenido de signo contrario presente de algún modo en el discurso previo (Ducrot 1986).

Dicha dependencia contextual, que apunta a una información anterior, tiene un objetivo comunicativo muy claro: se trata de cuestionarla, de discutirla para, en última instancia, rechazarla. En otras palabras, al igual que ocurría con créeme, nos situamos aquí en una perspectiva polifónica y polémica que nos lleva a centrarnos en otra voz, en otro punto de vista, con el propósito de cuestionar su validez.

Son factibles, aunque no hemos encontrado ningún ejemplo real, diálogos en los que en una primera intervención se haga explícito el contenido que en la intervención siguiente se rechaza mediante no creas: $-\mathrm{A}: p,-\mathrm{B}$ : no creas que $p, q$ ( $\rightarrow$ "no $p$ ”).

Lo normal, sin embargo, es que nos movamos en el territorio de lo implícito, es decir, que se rechacen informaciones que no se han manifestado de forma abierta en el discurso precedente. En realidad, para ser más exactos, se tiene aquí un movimiento que va de lo implícito a lo explícito: se incorpora al discurso un contenido implícito que luego se manifiesta de forma abierta para rechazarlo mediante la fórmula apelativa.

A veces la información que se cuestiona aparece bajo la forma de una implicatura razonable, es decir, como una deducción pragmática que fácilmente el interlocutor

8 La intervención se define como "Unidad monológica máxima estructural, asociada al cambio de emisor, que se caracteriza por ser o por provocar una reacción lingüística” (Briz y Grupo Val.Es.Co 2003: 17). 
podría haber derivado a partir de las palabras del locutor y de un contexto muy accesible. Es, por parte del hablante, una estrategia de prevención encaminada a cuestionar formas esperables de pensar: se anticipa, para dejar clara su improcedencia, a una muy probable creencia errónea del interlocutor:

(12) Actualmente mis novias son: Aurora, Lola, Nativel, Esperanza y Zulema.

No se crea que poseo un serrallo ambulante, no, nada más lejos de la realidad (García Sánchez 2003: 115).

En el siguiente ejemplo tenemos una situación mixta, en parte similar a la anterior (hay deducción pragmática) y en parte similar a la que se describirá en último lugar (se trata de una información que forma parte del contexto compartido):

(13) - Martín, no crea que porque me caiga usted bien no voy a hacer mi trabajo (Ruiz Zafón 2008: 445).

La proposición que desencadena todo el proceso se inserta en el decurso mediante una oración causal que apunta a una información conocida previamente y aceptada por ambos interlocutores ("me cae usted bien”), es decir, forma parte del contexto compartido. Sin embargo, el hablante, a fin de evitar malentendidos, ha considerado necesario hacerla explicita para desactivar una posible deducción no deseable ("como me cae usted bien, no voy a hacer mi trabajo”).

Consideremos ahora este otro caso:

(14) - Se le están subiendo a la chepa, Mercedes, y si a usted se le suben a la chepa se nos suben a todas a la chepa. Tengo mis informadores, no crea que no sé lo de la cancioncita, sé lo que pasa en la prisión a todas horas [...] (D. Chacón, La voz dormida, CREA).

Su particularidad reside en que el contenido que se explicita y rechaza no aparece como implicado pragmáticamente en el discurso inmediatamente anterior. Esto, sin embargo, no significa que no esté de algún modo sugerido. Sólo hay que manejar un contexto más amplio en el que se consideren la actuación y las palabras de la persona que ahora dice eso. Se trata de anular una información que podría derivarse de este contexto previo.

\subsubsection{No creas que... y la selección del modo}

Creer es un ejemplo paradigmático de "predicado transparente" que admite la anticipación de la negación (Creo que no ha llegado todavía $\approx$ No creo que haya llegado todavía $)^{9}$. Este comportamiento parece extensible a sus formas apelativas: Créeme que Pedro no tiene dinero $\approx$ No creas que Pedro tiene dinero.

Hay, sin embargo, algo llamativo en el enunciado apelativo con negación en el verbo principal (No creas que Pedro tiene dinero): mientras que en la versión

\footnotetext{
Esta naturaleza determina que las transformaciones “salten" por encima de este tipo de verbo (Bosque 1990: 30-35). Por otra parte, se debe tener presente que no hay en sentido estricto una relación de sinonimia entre el ejemplo con negación anticipada y el ejemplo con negación proposicional (Bosque 1980: 51).
} 
declarativa (No creo que Pedro tenga dinero) el verbo de la oración sustantiva está en subjuntivo, en la variante apelativa aparece el indicativo.

Sobre las motivaciones que están detrás de este comportamiento, pensamos que la razón principal se encuentra en la marcada dependencia contextual que implica el uso de la negación. No creas que Pedro tiene dinero solo tiene sentido si en el contexto previo se ha propuesto como verdadera la proposición "Pedro tiene dinero". El sentido polémico y polifónico de la negación conlleva, por tanto, una especie de cita. Hay que tener en cuenta que creer es un verbo que permite la disociación entre el punto de vista defendido por el sujeto del enunciado (el oyente) y el hablante o sujeto de enunciación, de modo que la oración sustantiva en indicativo solo puede recoger la postura del primero, no la del segundo, que mantiene exactamente la contraria.

En realidad, el comportamiento de no creas que..., en lo que se refiere a la selección del modo verbal de la oración sustantiva, es más complejo. Como muestra el siguiente ejemplo, el modo seleccionado también puede ser el subjuntivo:

(15) Bueno ese es el menor de mis problemas [...]. El verdadero problema es que hago con los pingüinos que tengo jugando en el salón, las focas que se empeñan en lavarme los platos de la fregadera [...] y el oso polar que se ha instalado en mi cuarto de baño. No, no creas que haya tomado alguna sustancia "rara" o que haya cargado demasiado mi whisky nocturno, no (http://www.goear.com/lyrics/57592/en-qu-estspensandofacebook-locucin-jess-crodoba-practicas-de-locucin)

También aquí el hablante rechaza una proposición, presente de algún modo en el contexto, que considera falsa. No manifiesta ningún tipo de incertidumbre con respecto a su falsedad. Si esto es así, la presencia del subjuntivo no responde a los mismos requisitos que cuando la oración sustantiva sigue a no creer en un ejemplo como No creo que Juan haya aprobado la oposición: aunque el hablante parece decantarse por la falsedad de la proposición “Juan ha aprobado la oposición”, tampoco descarta por completo que pueda ser verdadera. Es decir, el subjuntivo pone de manifiesto cierto grado de incertidumbre con respecto a la verdad de esta proposición. Se entra así en el dominio de la "hipoteticidad” como uno de los valores propios de la "no aserción".

Si el hablante no muestra ningún tipo de incertidumbre con respecto a la proposición que rechaza, cabría suponer que la aparición del subjuntivo responde más bien al punto de vista del oyente. De nuevo, hay que tener en cuenta el doble frente de evaluación epistémica que hay este tipo de ejemplos. En No creas que Juan haya aprobado la oposición sujeto de enunciado (tú) y sujeto de enunciación son distintos y sus juicios epistémicos pueden diferir. Para el sujeto de enunciación es falsa la proposición expresada por la oración sustantiva, pero ¿qué pasa con el sujeto del enunciado (tú) o, mejor, con la postura que el hablante le atribuye? Pensamos que le asigna un punto de vista que se mueve en una horquilla que va de la posibilidad a la probabilidad. Hay, pues, desde su punto de vista cierto grado de incertidumbre y el subjuntivo parece responder a este juicio epistémico. En otras palabras, el hablante rechaza, por considerarla falsa, una muy probable idea del oyente. Téngase en cuenta que no creas que suele introducir una deducción 
pragmática que fácilmente el interlocutor podría haber llevado a cabo. Sin embargo, nos movemos dentro del erritorio de lo probable, no de lo seguro y cierto ${ }^{10}$.

\subsection{No creas parentético}

Nos ocupamos ahora del análisis del uso parentético de la fórmula no creas:

[Un paciente con una enfermedad venérea acude al médico y hace el siguiente comentario]

(16) $-[\ldots]$ la tengo muy pequeña, pero no crea, "trabaja" muy bien y me da muchas satisfacciones. Por eso soy gozoso de la vida (Luis Jiménez de Diego, Memorias de un médico de Urgencias, CREA).

(17) - ¿Y qué demonios haces, si se puede saber? Que no podemos más de la curiosidad. -Eso, eso. Habla tú primero y luego te contamos los demás, porque aquí cada uno tiene algo que rascar, no creas (Lola Beccaria, La luna en Jorge, CREA).

Se observa que este no creas parentético puede aparecer como comentario marginal tanto al comienzo como al final de la proposición sobre la que actúa. Otra característica común es que la parte del discurso sobre la que incide transmite siempre un contenido asertivo pleno: no aparecen marcadores de modalidad epistémica que rebajen la fuerza del compromiso del hablante. Asimismo, la proposición a la que acompaña no puede iniciar el discurso. Es necesario que previamente haya, en el seno del diálogo, la intervención de otro hablante o que, en el marco de la intervención o de un discurso monologal, el emisor haya planteado algo que desencadene la aparición de no creas. Evidentemente, la responsabilidad del estrecho anclaje que los usos de no creas mantienen con lo planteado en el discurso previo recae en la presencia de la negación.

\subsubsection{La carga refutativa de no creas parentético}

Con relación al valor refutativo que cumple esta fórmula parentética, la información que se rechaza con ella se adscribe al territorio de lo implícito. Más en concreto, cumple la función de desactivar lo que, a los ojos del oyente, podría ser una implicatura que razonablemente se podría deducir de algo dicho por el hablante o, de un modo más general, del discurso precedente y del contexto en el que se enmarca:

Se podría aventurar para la aparición del subjuntivo otra explicación perfectamente compatible con la anterior. El subjuntivo, especialmente en contextos de alternancia modal, suele aparecer cuando se recoge una información ya presente en el contexto; en concreto, si nos hacemos eco de la propuesta de Rodríguez Rosique (2008), una información ya activada, es decir, aquella "que el hablante cree que su interlocutor tiene en mente, o sobre la que está pensando, en el momento de la comunicación” (2008: 68). Esta estrategia de poner en un segundo plano una información podría verse como una de las manifestaciones de la "no aserción” ligada al subjuntivo. Se puede presentar como ya activada información factual que se considera verdadera, como en: -A: Ha empezado a nevar, así que nos quedamos. -B: Pues aunque haya empezado a nevar, tenemos que ir, pero también información meramente hipotética: -A: Puede que empiece a nevar, así que tendríamos que quedarnos. -B: Pues aunque empiece a nevar, tenemos que ir. Teniendo en cuenta esto, en la selección del modo de la oración sustantiva que sigue a no creas encontramos la lucha entre dos tendencias: o se cita una aserción de la que se responsabiliza al oyente (indicativo) o se recoge una información atribuida al oyente que se considera falsa o, en todo caso, improbable y que se presenta como ya activada (subjuntivo). 
(18) [Una enfermera se sorprende de que una anciana siga fumando todavía a su edad] - Pues sí, hija, sí. Yo nací en Cuba y ya se sabe, allí las cosas eran de otra forma... por eso empecé a fumar a los once años. Nunca lo he dejado y ya llevo haciéndolo más de ochenta años. Todos los días me cae una cajetillita de Ducados y un par de puritos... [...]. Y no crea, me encuentro la mar de bien. Ni toso, ni me acatarro... ni nada (Luis Jiménez de Diego, Memorias de un médico de Urgencias, CREA)

Se observa que en la primera parte de la intervención la señora ofrece una serie de informaciones (empezó a fumar siendo niña, lleva fumando más de ochenta años...) que junto con la información contextual disponible (ha acudido a un servicio de urgencias) podrían llevar al oyente a deducir que no se encuentra nada bien. Esta proposición sería una implicatura o deducción pragmática. La fórmula y no crea la desactiva refutándola. El enunciado declarativo que sigue a dicha fórmula presenta la alternativa a esa implicatura bajo la forma de una rectificación que la contradice. En otras palabras, el hablante se anticipa y trata de evitar un posible error de interpretación del oyente.

El siguiente esquema trata de representar la estructura conceptual subyacente:

"Empecé a fumar a los once años. Nunca lo he dejado y ya llevo haciéndolo más de ochenta años..." + contexto [la mujer ha acudido a urgencias] $\rightarrow$ implicatura razonable [el oyente puede pensar que "no me encuentro muy bien”]. Y no crea (refutación de la implicatura) [que no me encuentro muy bien], me encuentro la mar de bien (rectificación de la implicatura).

Si se dejan a un lado los aspectos concretos, se tiene finalmente la siguiente estructura:

$q \rightarrow[$ no $p]$, no creas [que no $p], p$

En este esquema conceptual, las proposiciones marcadas con negrita son las únicas que se comunican de manera explícita, las que aparecen en cursiva y entre corchetes son implicaturas. Además, mientras que las rectificaciones finales son responsabilidad del hablante, las implicaturas que las desencadenan no se pueden asignar de manera automática al oyente, sino que más bien representan, a ojos del hablante, lo que el oyente podría deducir a partir de la información disponible.

\subsubsection{Un cambio en marcha: del valor refutativo al de refuerzo de la aserción}

En este uso de no creas, las implicaturas subyacentes, que forman parte de lo probable, no se hacen nunca explícitas por la sencilla razón de que están implicadas de manera automática -obviamente, para ser rechazadas- por la rectificación. En todo esto parece intervenir un principio pragmático de eficiencia en la gestión de la información. Como no es posible mantener una proposición $p$ y su contraria no $p$, al comunicar de forma explícita $p$, doy a entender que no es el caso que no $p$, y viceversa. En otras palabras, si con un enunciado más sencillo comunico lo mismo que con una estructura mucho más compleja, ¿por qué decantarme por una opción más costosa desde el punto de vista del procesamiento si los efectos cognitivos son los mismos?

Pues bien, pensamos que es precisamente esta necesidad de no tener que comunicar de manera explícita lo que se deduce sin problemas a partir de lo que sí se comunica 
explícitamente la que está detrás del cambio semántico que se está verificando en los usos parentéticos de no creas. Dado que si defiendo $p$, sugiero de forma automática que rechazo la opción contraria no $p$ (y viceversa), en el caso de los usos de no creas, $p$ y no creas, no $p$, la fórmula no creas, sin perder todavía el valor de refutación de una implicatura subyacente, va camino de convertirse en una especie de operador de refuerzo asertivo de la proposición que se comunica de manera explícita, esto es, la proposición a la que acompaña y que en el marco del discurso funciona como rectificación. En este sentido, resulta sintomático que no creas se pueda sustituir fácilmente por créeme parentético o un marcador como la verdad.

\subsubsection{No creas parentético y la construcción no creas que...}

Si se compara Créame, no me encuentro bien con Créame que no me encuentro bien, sus condiciones de uso son las mismas. En cambio, la variante con el verbo epistémico negado en construcción parentética (Y no crea, me encuentro bien) nada tiene que ver con Y no crea que me encuentro bien, sino con Y no crea que no me encuentro bien. Para profundizar en la relación semántica entre estas dos variantes, nos apoyaremos en un ejemplo en el que la proposición afectada es negativa:

(19) - Ya sé que no tienes ninguna fe en nosotros, Vila. No me molesta, no te creas. Suele pasaros a todos los que habéis nacido al norte de aquí (Lorenzo Silva, El alquimista impaciente, CREA).

Se observa que es fácil transformarlo en una nueva versión con la construcción no te creas que... en la que la oración sustantiva carece de negación:

(20) - Ya sé que no tienes ninguna fe en nosotros, Vila. No te creas que me molesta. Suele pasaros a todos los que habéis nacido al norte de aquí.

Semánticamente, también aquí, como en el caso de no creas parentético, hay una referencia a contenidos implícitos sin los cuales esta construcción tampoco podría utilizarse de modo adecuado. Asimismo, también se rechazan y refutan tales contenidos.

¿En qué se distinguen estas dos estructuras con no creas? La respuesta es que no creas que... rechaza de forma abierta el supuesto implícito que alguien, preferentemente el oyente, podría derivar de las palabras del hablante que preceden a esa fórmula. Se tendría la siguiente estructura conceptual ${ }^{11}$ :

\section{$q \rightarrow[p]$ (implicatura probable del oyente), no creas que $p[\rightarrow$ no $p]$}

Aplicada al ejemplo particular que se está analizando, quedaría así: "Ya sé que no tienes ninguna fe en nosotros $\rightarrow$ [el oyente piensa que "esto me molesta"] (implicatura probable). No creas que me molesta $[\rightarrow$ no me molesta $]$ ".

Hay en esta estructura un recorrido que va de $p$ a no $p$ : se empieza en el plano de la información implícita ( $p$ es un supuesto que, razonablemente, se puede deducir

Se representan en negrita las proposiciones que se comunican de manera explícita. En cursiva y entre corchetes las proposiciones implícitas. 
de lo que el hablante ha dicho); a continuación, ya en el plano explícito, se refuta, mediante no creas que..., ese mismo supuesto. Finalmente, la refutación de $p$, nos lleva a deducir, de nuevo en el plano implícito, como verdadera su contraria no $p$.

En cambio, la fórmula parentética se apoya en esta estructura conceptual:

$q \rightarrow[p]$ (implicatura del oyente), no $p$ (rectificación del hablante), no creas $[p]$

(Ya sé que no tienes ninguna fe en nosotros $\rightarrow$ [el oyente piensa que "esto me molesta"]. No me molesta, no te creas [que me molesta]).

En este caso, el recorrido se desarrolla mediante estos pasos: dentro del dominio de la información implícita, $p$ es un supuesto que es probable que se deduzca de lo que el hablante ha dicho. A continuación, el hablante expresa ya de forma explícita una rectificación que es un supuesto contrario a esa implicatura inicial. Por último, mediante no creas (parentético) se rechaza de modo implícito esa misma implicatura.

En definitiva, las dos estructuras sirven para decir lo mismo, pero siguiendo recorridos distintos y poniendo el énfasis en aspectos distintos. Las diferencias se encuentran en el plano informativo y en el "peso" perceptivo que se otorga en cada caso a los diversos componentes involucrados. No creas que... se centra en la implicatura subyacente para refutarla de forma explícita. Conforme a los principios pragmáticos y las reglas de cálculo de inferencias, si se rechaza $p$, es lícito deducir la verdad de su contraria (no p). Esta deducción pragmática actuaría al modo de una rectificación implícita. En cambio, no creas parentético otorga relevancia informativa a la rectificación, que se afirma de forma explícita, y a partir de ella se rechaza como falsa la proposición contraria, es decir, el supuesto implícito que da lugar a todo el proceso.

\subsection{No creas en el marco de la unidad conversacional del intercambio}

\subsubsection{El anclaje explícito de la refutación asociada a no creas}

Nos interesa el uso de no creas en contextos como los siguientes ${ }^{12}$ :

(21) -Tú vives bien

-No creas, regular nada más (Steel 1976: 63).

(22) MERCEDES.- (Subiendo el tono.) Le decía que me imagino que se sentirán ustedes muy mal con esta dramática situación, ¿no?

ADELA.- Bueno, no crea. Nos hemos acostumbrado y vamos tirando (...) (Paloma Pedrero, El pasamanos, CREA).

(23) J: de todas formas/ tú// en un estado/ totalmente democrático $\rightarrow$ [como Estados Unidos $\uparrow=]$

$\mathrm{S}$ :

$\mathrm{J}:=$ allí no entra nadie sin un mandamiento [judicial]

[NO puede hacer eso]

A:

[no creas]§ (Briz coord. 1995: 193)

12 A este uso se refiere Santos (2003: 289) en la segunda acepción que ofrece de no creas. 
Este uso comparte con los descritos anteriormente la característica de que también aquí se aceptan como verdaderas ciertas proposiciones y se rechazan otras como falsas. Se diferencia de ellos en que no creas se integra en el marco de la unidad del intercambio, en concreto, en el seno de una intervención reactiva que exige la presencia de una intervención previa iniciativa a la que responde. En este contexto, no creas, o bien inicia, si se dejan fuera ciertos marcadores conversacionales, la intervención que rectifica lo que el interlocutor ha dicho, o bien constituye por sí sola turno.

También en este tipo de uso la dependencia contextual es clara e inequívoca. Se rechaza una información presente de algún modo en el contexto previo, información con la que el nuevo hablante polemiza. Ahora bien, mientras que en los usos anteriores la proposición que se rechaza se presentaba, al menos inicialmente, como implicatura probable, en este uso la proposición que se refuta con la fórmula apelativa tiene que haberse planteado de forma explícita en la intervención inmediatamente anterior.

\subsubsection{La correspondencia funcional entre los usos asociados al intercambio y los usos parentéticos de no creas}

Teniendo en cuenta las relaciones que se aprecian entre las diversas manifestaciones de no creas, planteamos la siguiente hipótesis: que los usos parentéticos tienen su fundamento en los usos adscritos al intercambio. Según esto, los últimos se podrían considerar más básicos y, en cierta medida, modelo para los primeros. No en vano, en el uso del lenguaje, el diálogo tiene algo de esencial y primigenio, y el resto de manifestaciones discursivas derivan de él.

De los usos parentéticos hemos destacado dos características: a) una naturaleza polémica (se cuestiona cierta información); b) la información que se rechaza es algo que el interlocutor podría deducir a partir de lo que el hablante ha dicho o de su conocimiento del mundo. En virtud de ellas, se puede sostener que el hablante está manteniendo una especie de "diálogo implícito" con otro punto de vista al que tiene presente y al que, de alguna manera, está respondiendo. En otras palabras, los usos parentéticos sintetizan o reducen a una sola intervención lo que los usos dialógicos adscritos a la unidad del intercambio expresan en dos intervenciones distintas.

$\mathrm{Si}$ se asigna a los usos adscritos al intercambio la organización conceptual " $-\mathrm{A}$ : $p,-\mathrm{B}$ : no creas $[p], q[\rightarrow$ no $p]$ ], los usos parentéticos reducen este esquema a una intervención, aunque siguen incorporando dos voces distintas:

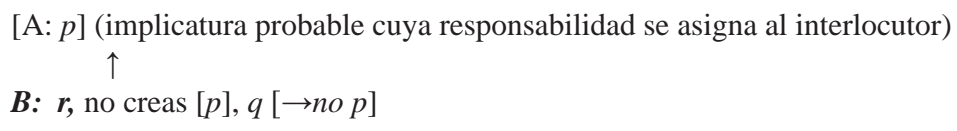

En los dos usos se está rechazando cierta proposición y reforzando la contraria. La diferencia se encuentra en el distinto peso o relieve informativo que se otorga a esos dos componentes. En el uso ligado al intercambio, la proposición que se rechaza se adscribe al dominio de lo explícito, mientras que la que, al funcionar como rectificación, se refuerza puede quedar implícita o comunicarse de forma explícita. En cambio, en los usos parentéticos la información que se rechaza se integra en el dominio de lo implícito y la que se apoya siempre forma parte del contenido explícito del mensaje. 
Si la hipótesis que se ha planteado es correcta ¿cómo se ha podido producir el paso de uno a otro? Como se recordará, en un uso parentético como este:

(24) Tal vez no sea muy normal, para usted, pero es una forma de vivir como cualquier otra. Y no crea, tiene sus ventajas (Steel 1976: 29).

no crea refuerza la proposición a la que acompaña. Su comportamiento se aproxima al de un operador que reafirma la verdad de la proposición con la que aparece.

En realidad, el germen de esta dinámica de refuerzo ya está en los ejemplos en que no creas, dentro de una intervención reactiva, precede a una rectificación, tal como ocurre en el ejemplo 20 que repetimos:

\section{(20) -Tú vives bien}

-No creas, regular nada más (Steel 1976: 63).

En este tipo de uso, no creas, a la par que discute lo planteado en la intervención iniciativa, introduce una rectificación que se ve así reforzada. Ahora bien, al mantener no creas un anclaje contextual explícito con la proposición, presente en la intervención iniciativa, que se cuestiona, es el aspecto de rechazo polémico el que predomina. En cambio, en los usos parentéticos ese anclaje contextual es implícito (se discute una proposición que no se comunica de forma abierta) y todo el peso perceptivo y conceptual se centra en la rectificación, lo cual facilita que la fórmula parentética no creas acabe actuando a la manera de un operador de refuerzo de la misma.

La relación entre los usos parentéticos de no creas y los adscritos al intercambio se aprecia en el hecho de que se puede pasar fácilmente de una formulación a otra. $\mathrm{Si}$, por ejemplo, queremos ir de los primeros a los segundos, se tiene que desdoblar el enunciado afectado en varias intervenciones y hacer explícita la proposición que se rechaza. De acuerdo con esto, el ejemplo 23 se podría reescribir como:

(25) A: Tal vez no sea muy normal para usted, pero es una forma de vivir como cualquier otra.

B: Sí, pero no tiene ninguna ventaja.

A: No crea, tiene sus ventajas

\section{LÉXICO, GRAMÁTICA Y DISCURSO}

$\mathrm{Al}$ analizar los usos discursivos de créeme y no creas hemos pretendido mostrar cómo esas formas verbales se ponen al servicio del discurso, es decir, acaban contribuyendo al desarrollo de algunas operaciones básicas constitutivas del mismo (presentar como verdaderas ciertas representaciones, aceptar unas y rechazar otras, influir sobre el entorno cognitivo del interlocutor, facilitar el cálculo de inferencias...).

Aparentemente, estamos ante medios de expresión léxica que se encuentran al margen de los procedimientos gramaticalizados y, en particular, fuera de la categoría de los marcadores del discurso ${ }^{13}$. Sin embargo, no por ello deja de ser interesante

3 Los marcadores del discurso suelen caracterizarse como una categoría "pragmática” (Landone 2009: 76) o funcional (Pons Bordería 2000: 201) en la que se integran unidades muy diversas que, en ocasiones, cumplen la función de 
analizar en qué términos se concreta su contribución a la gestión del discurso. Además, como ha puesto de relieve la teoría de la gramaticalización, existe un continuum entre léxico y gramática, y diacrónicamente se ha dado un paso gradual entre ambos ${ }^{14}$.

Aunque en el caso particular de las formas analizadas todavía no se puede hablar de gramaticalización, al menos en sentido estricto, funcionalmente, en el plano del discurso, hay puntos de contacto entre la categoría de los marcadores discursivos y esas formas verbales que nos parecen interesantes. A continuación destacamos algunos.

\subsection{Naturaleza metadiscursiva o metatextual}

Los marcadores del discurso pertenecen a un nivel meta (metacomunicativo, metadiscursivo, metatextual...). Es decir, quedan al margen del contenido proposicional y pasan a constituir una mirada reflexiva sobre los procesos que configuran el discurso. Verschueren (2002: 300) los encuadra entre los "indicadores de conciencia metapragmática”. También créeme y no creas se sitúan fuera del contenido proposicional y actúan como llamadas de atención dirigidas al oyente para que procese cierta representación del mundo y tenga en cuenta las consecuencias que se derivan de considerarla verdadera o falsa. Todo ello orientado hacia el propio acto de habla en curso y los procesos que lo generan.

\subsection{Conexión}

Una de las propiedades que se suelen considerar a la hora de caracterizar los marcadores del discurso es su capacidad de conectar o relacionar entidades o elementos de muy diversa naturaleza. Se trata de una interpretación muy amplia de lo que puede representar la conexión, tan amplia que da cabida tanto a la conexión sintáctica como a la lógico-semántica, la pragmática-discursiva o la argumentativa, y esta relación se puede establecer entre elementos explícitos o implícitos, contiguos o separados,

marcación del discurso. Tal función abarcaría tanto la organización del discurso como la gestión conversacional y el procesamiento de inferencias. Tienen, pues, una naturaleza procedimental, es decir, "codifican instrucciones de procesamiento" (Leonetti y Escandell 2004: 1728). En la categorización pragmática no se puede hablar de criterios discretos, sino de un continuum escalar en el que podemos encontrar tanto realizaciones prototípicas como periféricas. En esta línea, Pons Bordería (1998: 59-60) propone un prototipo con un doble centro categorial. Otro acercamiento a los “conectores parentéticos” desde la teoría de los prototipos se puede encontrar en Cuenca (2001).

14 Desde una perspectiva diacrónica, la gramaticalización se define como "the process whereby lexical items and constructions come in certain linguistic contexts to serve grammatical functions, and, once grammaticalized, continue to develop new grammatical functions” (Hopper y Traugott 1993: XV). En tal proceso de evolución no solo hay cambios formales que implican un cambio de categoría (de una categoría léxica se pasa a una gramatical), sino también de naturaleza semántica.

Es evidente que si se defiende la existencia de un proceso de gramaticalización que ha conducido a la aparición de un marcador del discurso, no se está hablando de gramaticalización en el sentido más clásico del término, es decir, entendido como el paso de una categoría léxica a una categoría morfológica. Autores como Traugott (1995b), Brinton (2007) y Company (2004), entre otros, han ampliado el concepto de gramaticalización para dar cabida a los cambios experimentados por ciertos términos léxicos que han acabado por transformarse en marcadores del discurso. La última de las autoras citadas (2004: 65) considera necesario reconceptualizar el término para darle una interpretación más amplia, de modo que presentaría rasgos compartidos con la gramaticalización más clásica pero también otros exclusivos que tendrían su origen en un proceso de subjetivación que implicaría, además de un cambio semántico (- subjetivo > + subjetivo), una pérdida o desintegración de las propiedades sintácticas originales. 
pertenecientes a la lengua o al contexto, al enunciado o a la enunciación... ${ }^{15}$. Partiendo de esta concepción extensa, no hay problema en defender que en el caso de créeme y no creas, la conexión es de naturaleza no solo lógico-semántica (hay una relación implícita de causa-consecuencia entre proposiciones), sino también pragmáticodiscursiva, dado que aquella relación se plantea para rechazarla y polemizar con quien la defiende, y argumentativa, ya que se favorecen ciertas conclusiones y se desestiman otras.

\subsection{Representar / procesar}

Desde la teoría de la relevancia (Blakemore 1992: 149-150; Wilson y Sperber 1993) se ha planteado la distinción entre información conceptual (la que contribuye a las condiciones de verdad de la proposición expresada) y la información de procesamiento (indica cómo ha de ser manipulada la primera). En su representación más prototípica, los marcadores del discurso se adscribirían a la segunda de ellas $^{16}$. En este contexto se entienden definiciones como la de Portolés (1998: 25-26) (los marcadores se encargan de guiar las inferencias que se realizan en la comunicación) o la de Montolíu Durán (1998: 109) (son pistas que el hablante utiliza a fin de dirigir cooperativamente el proceso interpretativo del interlocutor). Sin embargo, todo apunta a que estamos ante una cuestión de grado. Desde una perspectiva diacrónica, la teoría de la gramaticalización ha puesto de relieve que el significado procedimental de muchos marcadores ha derivado, a través del proceso de subjetivación o pragmatización ${ }^{17}$, del significado léxico original (Traugott 1995b; Brinton 1996; Brinton 2007, Company 2004; Alvarado Ortega y Ruiz Gurillo 2011). Sincrónicamente, también se ha constatado que algunos marcadores conservan restos

5 Para un análisis bibliográfico general sobre lo que representa la conexión en la definición de los marcadores del discurso, puede consultarse Landone (2009: 84-88). Por nuestra parte, queremos destacar que autores como Pons Bordería (1998) o Cuenca (2001) acuden al concepto de conexión, eso sí, desde los planteamientos de la categorización no discreta que se defiende desde la teoría de los prototipos, para fundamentar la categoría de los conectores (Pons Bordería) o conectores parentéticos (Cuenca). Según Pons Bordería (1998: 204), las formas que expresan conexión pueden situarse en el centro, la periferia o la zona de transición de esa función. Aquellas formas en las que la función de conexión aparece asociada a otras funciones (como la modalidad o la formulación) actuarían como conectores periféricos. Otros autores parecen circunscribir la función de conexión solo a algunos elementos, precisamente aquellos que denomina conectores (Portolés 1998; Martín Zorraquino y Portolés 1999). En realidad, para los últimos autores, la función de conexión parece estar presente no solo en los que denominan conectores sino también en otros como se desprende de esta cita: "existen marcadores que relacionan por su significado dos o más miembros del discurso frente a otros cuyo significado sólo afecta a un miembro del discurso. A estos últimos los denominaremos 'operadores', los primeros son la mayor parte de los usos de los marcadores que denominaremos 'estructuradores de la información' (...) , 'conectores’(...) y 'reformuladores”’ (1999: 4072). Fuentes Rodríguez (2009: 12) distingue, dentro de las unidades que actúan más allá de la oración, entre conectores (relacionan varios enunciados) y operadores (su ámbito se reduce a un solo enunciado). También Llorente Arcocha opta por esta distinción, aunque considera que sus "operadores discursivos" son conectores en un sentido amplio del término (1996: 14), siempre que se vaya más allá de la conexión lógico-semántica y se atienda a la de naturaleza discursivopragmática que consiste en relacionar acciones y organizar su secuencia.

16 En su definición de los marcadores del discurso, Fraser (1999: 950) destaca lo siguiente: "They have a core meaning which is procedural, not conceptual”.

17 Traugott (1995a: 32) define el proceso de subjetivación como "un fenómeno gradual, por el cual formas y construcciones que inicialmente expresaban, en primera instancia, significados concretos, léxicos y objetivos, llegan a realizar, a través de un uso repetido en contextos sintácticos locales, funciones progresivamente más abstractas, pragmáticas y basadas en el emisor”. La traducción de esta cita está tomada de M.J. Cuenca y J. Hilferty (1999: 163). 
de significado conceptual y que este condiciona su valor de procesamiento ${ }^{18}$. Se replantean así los límites de la categoría y se admite la inclusión de formas cuyo valor léxico (conceptual) se mantiene todavía vivo.

En lo que se refiere a créeme y no creas, estas formas son un ejemplo claro de que expresiones con significado conceptual pueden ayudar, sin contribuir a las condiciones de verdad de la proposición que se quiere comunicar, al procesamiento de cierto contenido representativo. En realidad, para ser exactos, combinan en su seno tanto un componente conceptual (su significado léxico) como procedimental (su significado apelativo) y juntos orientan el procesamiento de la representación del mundo a la que acompañan de dos maneras: 1) presentándola, según el caso, como verdadera o falsa y 2) influyendo sobre el interlocutor para que la acepte como tal.

\subsection{Significados, funciones y ámbitos de actuación}

Landone (2009) propone para caracterizar los marcadores discursivos un modelo tridimensional en el que se tienen en cuenta estos aspectos: 1) Posibilidad de distinguir un significado básico o nuclear, 2) la existencia de diversas funciones ligadas al contexto y resultado de amoldar ese significado primario a las intenciones del hablante y 3) posibilidad de actuar, incluso de forma simultánea, en varios niveles o planos.

Podemos aplicar al análisis de créeme y no creas este modelo tridimensional.

En efecto, al tratarse de procedimientos no gramaticalizados o al menos no plenamente gramaticalizados, su significado léxico y modal está vivo y se encuentra en la base de los diferentes usos discursivos. Hay una clara motivación. Al primero le corresponde la modalización asertiva y al segundo el componente interactivo. A ese núcleo sémico original y primario se han ido añadiendo otros contenidos que ya permiten adscribir de un modo claro los valores descritos al plano de las operaciones discursivas. Nos referimos a aspectos como “orientación metadiscursiva”, "desacuerdo" (como resultado de su naturaleza polémica y refutativa), "intensificación o refuerzo expresivo"19 y "focalización”"20. Al no haber habido gramaticalización no podemos hablar todavía en sentido estricto de codificación, sino en todo caso de “convención de uso” (Morgan 1978), es decir, estamos ante algo que es esperable, normal que se produzca en ciertos contextos, pero no ante una pauta estricta de

18 Pons Bordería (1998: 56), a la hora de caracterizar el prototipo de conector, plantea la siguiente característica: "Si posee significado léxico pleno, no es conector". Sin embargo, la acaba matizando (1998: 57): "No en todos los casos el vaciado semántico es total". Por su parte, Llorente Arcocha (1996: 290) no tiene ningún problema en afirmar que "existe una clara motivación semántica en el uso de muchos de ellos. Dicho de otro modo: el valor discursivo de ciertos operadores es deducible (composicionalmente o no) de su significado". Un ejemplo de esto sería el uso conversacional de ya (te/le) digo. No es imprescindible que haya una desviación semántica clara (aunque sí otros requisitos) para que una construcción acabe funcionando como operador.

19 Si con un enunciado como Se ha marchado puedo conseguir el mismo efecto cognitivo que con Créeme, se ha marchado (convencer al interlocutor de la verdad del hecho comunicado), ¿por qué, llegado el caso, el hablante se decanta por la opción que implica un mayor esfuerzo de procesamiento? La respuesta es que el hablante pretende reforzar ese efecto cognitivo sacándolo del ámbito de lo implícito.

20 Gutiérrez Ordóñez (1997: 34) define foco como "un punto en el que convergen los vectores intencionales del emisor. Su propósito comunicativo suele ser el de llamar la atención del receptor con el fin de vencer en este una predisposición contraria o simplemente de subrayar su importancia en el proceso informativo en el que se hallan inmersos”. Fuentes Rodríguez (1999: 48) llama la atención sobre la función de focalización que pueden realizar los elementos apelativos. 
codificación. No son valores asociados de forma necesaria, por la gramática del español, a las formas verbales créeme y no creas, sino a ciertas apariciones suyas en el marco del discurso ${ }^{21}$.

Si pasamos ahora a ocuparnos de las funciones que pueden desarrollar estas formas, créeme que... y créeme parentético son semánticamente equivalentes y aparecen en distintos contextos en los que, sin embargo, cumplen la misma función de reforzar una proposición frente a otra, de signo contrario, presente en el contexto. El caso de no creas es más complejo. Según en el nivel sintagmático en el que se integre y el marco discursivo en el que aparezca, así también surgen valores que, aunque no son exactamente equivalentes, tampoco dejan de estar relacionados.

Finalmente, créeme y no creas parecen actuar simultáneamente en los diferentes planos o niveles que intervienen en la construcción de un discurso.

En primer lugar, las formas analizadas contribuyen a organizar el material lingüístico con el objeto de producir un mensaje cohesionado (operaciones relativas a la selección de información y a la manera de presentarla). Las diversas apariciones de créeme y no creas comparten la característica de que no pueden iniciar un texto, sino que sirven para marcar la dependencia con relación a otros segmentos discursivos en los que, de algún modo, está presente información que se cuestiona. En otras palabras, conectan ciertas proposiciones con otras para configurar una unidad superior coherente y cohesionada. Por otra parte, las distintas apariciones de créeme y no creas permiten presentar, en función de la intencionalidad del hablante, la misma realidad extralingüística y las mismas relaciones conceptuales bajo formulaciones diferentes. Por último, todas estas expresiones apelativas presentan la característica de que sirven para focalizar o realzar cierta información como alternativa a otra presente en el contexto.

En segundo lugar, no creas y créeme juegan un importante papel en el plano del procesamiento inferencial y argumentativo. Es sabido que buena parte de la información que transmitimos es de naturaleza implícita, información que al interactuar con la transmitida de manera explícita da lugar al desarrollo de procesos inferenciales que contribuyen a la creación de un texto coherente. Los marcadores del discurso son algunos de los procedimientos o señales que ayudan a guiar el proceso de interpretación del destinatario. Por otra parte, desde la Teoría de la Argumentación (Anscombre y Ducrot 1988), se insiste en que, a la hora de encadenar los enunciados, se están presentando argumentos que conducen a una determinada conclusión. Es decir, los enunciados están orientados argumentativamente, en el sentido de que favorecen ciertas continuaciones y, en cambio, dificultan otras. Los marcadores se conciben entonces como instrucciones semánticas que ayudan a que este proceso se desarrolle con éxito.

En el análisis de los valores discursivos de no creas y créeme, hemos podido comprobar el estrecho anclaje que estas formas mantienen con ciertos contenidos implícitos presentes de algún modo en el contexto ${ }^{22}$. En concreto, se trata de desactivar

${ }^{21}$ En esta perspectiva lo determinante es la función: "we should not ask whether a given form is a pragmatic marker or not, but rather whether a given use of a given form can be considered a pragmatic marker" (Aijmer, Foolen y SimonVandenbergen 2006: 102).

22 Salvo en el caso de no creas adscrito a la unidad del intercambio que se apoya en información explícita comunicada en la intervención iniciativa a la que responde. 
implicaturas probables para ofrecer una alternativa más fuerte, más válida, que es la que determina la continuación del discurso y en la que, por tanto, se fundamenta su coherencia. Conceptualmente, este esquema de organización discursiva se asemeja a una estrategia de contraargumentación al introducir dos puntos de vista opuestos: una parte del discurso nos lleva hacia una determinada dirección, la que le sigue nos lleva hacia la contraria (Anscombre y Ducrot 1977). De ahí que sea relativamente frecuente que esas formas aparezcan asociadas a marcadores de naturaleza contraargumentativa. Con todo, hay que reconocer que la cercanía que los valores de no creas y créeme presentan con los marcadores contraargumentativos se debe a que el uso de esas formas apelativas se enmarca en un contexto polifónico de refutación que conduce al desacuerdo: el hablante necesita reafirmar cierta proposición porque hay algo en el entorno del enunciado que así lo aconseja como puede ser una argumentación subyacente no deseada (el hablante plantea una proposición que puede llevar a una conclusión que no acepta), pero también la presencia de un contexto o incluso la realización de cierto acto de habla que puede generar implicaturas no deseadas.

En tercer lugar, no podemos olvidarnos del papel ejercido por estas formas en el plano interactivo o de las relaciones interpersonales. No creas y créeme están claramente orientadas hacia el interlocutor: el hablante trata de influir sobre él, busca alterar su entorno cognitivo a fin de que acabe pensando lo mismo que él. Curiosamente, no creas y créeme, que nacen de la polémica y la refutación, persiguen, en última instancia, el acuerdo con el interlocutor, dado que se intenta que este acepte como válida cierta representación de la realidad.

Esta orientación relacional e interactiva se manifiesta también claramente en la estrecha relación que existe entre los usos discursivos de no creas y créeme y el diálogo. En el caso de no creas adscrito a la unidad del intercambio esto es así siempre: se inserta de modo necesario en una intervención reactiva. En este marco, no creas desarrolla valores ligados a la cortesía verbal: expresa un rechazo atenuado. El resto de usos pueden aparecer tanto en discursos monologales como dialogales. Sin embargo, con independencia de ello, en la explicación de su comportamiento hemos de recurrir a la presencia de un “diálogo” implícito entre dos puntos de vista contrapuestos.

Por último, no creas y créeme son un exponente de la modalidad, y, en concreto, de la actitud epistémica que el hablante manifiesta con relación a ciertas representaciones del mundo. Se postulan como verdaderas ciertas proposiciones y se rechazan otras como falsas.

\section{5. ¿Fórmulas léxicas o marcadores?}

En nuestro análisis del comportamiento discursivo de créeme y no creas hemos insistido en el paralelismo funcional que se aprecia entre esas fórmulas verbales y la categoría de los marcadores discursivos. Llegados a este punto, parece obligatorio plantearnos la siguiente pregunta: ¿estamos ante fórmulas verbales apelativas que han terminado por constituirse en genuinos marcadores del discurso? Hay que reconocer que la gramática del español nos ofrece unos cuantos ejemplos de la evolución de una forma verbal apelativa hacia el territorio de los marcadores discursivos y, en consecuencia, el caso particular que nos ocupa no tendría nada de excepcional. Sin embargo, el comportamiento de créeme y no creas parece rehuir 
una categorización discreta, basada en el cumplimiento de una serie de condiciones necesarias y suficientes, y parece más bien requerir una perspectiva en la que se asuma la posibilidad de que se cumplan solo algunas de esas condiciones y en grados diversos. Según esto, es evidente que tales fórmulas verbales no se acomodan al prototipo de marcador discursivo ${ }^{23}$, sino que junto a propiedades que lo acercan a él, presentan otras que lo distancian de ese modelo cognitivo:

Tabla 2

\begin{tabular}{|l|c|c|c|c|c|}
\hline & $\begin{array}{c}\text { No creas } \\
\text { arentético }\end{array}$ & $\begin{array}{c}\text { No creas } \\
\text { (intercambio) }\end{array}$ & $\begin{array}{c}\text { Créeme } \\
\text { parentético }\end{array}$ & No & $\begin{array}{c}\text { No creas } \\
\text { que }\end{array}$ \\
\hline $\begin{array}{l}\text { Función asociada al discurso en alguno de sus } \\
\text { planos }\end{array}$ & Sí & Sí & Sí & Sí & Sí \\
\hline Independencia fónica y entonativa & Sí & Sí & Sí & No & No \\
\hline Carácter extrapredicativo & Sí & Sí & Sí & No & No \\
\hline $\begin{array}{l}\text { Conexión (semántica, pragmática, contextual, } \\
\text { textual) }\end{array}$ & Sí & Sí & Sí & Sí & Sí \\
\hline Pérdida del significado léxico & Sí-No & No & No & No & No \\
\hline Modificaciones semánticas (idiomaticidad) & Sí-No & No & No & No & No \\
\hline Al margen del significado proposicional & Sí & Sí & Sí & Sí & Sí \\
\hline Fijación formal & Sí-No & Sí-No & Sí-No & No & No \\
\hline Movilidad & Sí & No & Sí & No & No \\
\hline Combinación con conjunciones copulativas & Sí & No & Sí & Sí & Sí \\
\hline Autonomía & No & Sí & No & No & No \\
\hline $\begin{array}{l}\text { Está asociado convencionalmente a cierta función } \\
\text { pragmática }\end{array}$ & Sí & Sí & Sí-No & No & No \\
\hline
\end{tabular}

A continuación insistimos en alguna de ellas y en la importancia que tienen de cara a su categorización como marcadores del discurso.

Semánticamente, nos encontramos ante unas fórmulas plenamente transparentes. No son idiomáticas y el significado del conjunto es el resultado de la suma del de sus componentes. La única excepción parece plantearla el no creas parentético: aunque el componente apelativo y refutativo está todavía en la base de su valor discursivo, este ha ido evolucionando hacia la función de refuerzo asertivo. En su caso se podría hablar de "fórmula semiidiomática”, en el sentido de que ese nuevo valor está basado en el significado original de la fórmula, significado que de alguna forma sigue latente ${ }^{24}$.

La consecuencia de este carácter no idiomático o no plenamente idiomático es que hay una pervivencia del significado conceptual ligado al verbo creer, lo cual lo aparta de esa imagen prototípica de los marcadores discursivos como formas con

23 En realidad se puede decir que existen tantos prototipos de marcador del discurso como planteamientos existen sobre ellos. Cuando hablamos de "prototipo" nos referimos más bien a un conjunto de propiedades que suelen concitar cierto acuerdo.

24 Zuluaga (1980: 134) defiende que se puede hablar de grados de idiomaticidad. En las expresiones semiidiomáticas "los significados de los componentes inciden en el sentido global de la expresión, pero este no se identifica, sin más, con el literal-regular”. 
significado procedimental. Ahora bien, el que estas formas apelativas del verbo creer mantengan claramente el significado léxico en sus usos metadiscursivos no es de extrañar dado que su naturaleza asertiva (y apelativa) se aviene perfectamente a sus cometidos discursivos.

Desde un punto de vista formal, no se puede defender que se haya alcanzado una fijación completa ${ }^{25}$. Existe la posibilidad de variación en los morfemas de número y de persona. Sin embargo, tampoco se puede hablar de entera libertad: existe un repertorio limitado de formas y en algunos casos resulta difícil y en otros imposible introducir nuevos argumentos, sintagmas o complementos. Teniendo en cuenta esto, se podría proponer que en el caso de los tres primeros usos recogidos en la tabla estamos ante fórmulas semifijadas.

La falta de fijación completa nos aleja del que parece el comportamiento prototípico de los marcadores discursivos. Sin embargo, no faltan autores que se decanten por una visión más amplia en la que se admita cierto capacidad de variación morfológica y sintáctica. Por ejemplo, autores como Martín Zorraquino y Portolés (1999) o Pons Bordería (1998), a la hora de caracterizar marcadores de base apelativa como oye, mira, reconocen la posibilidad de que varíen los morfemas de número y persona y que se introduzca un sujeto.

En otro orden de cosas, es evidente que las construcciones no creas que... y créeme que... actúan en el ámbito de la modalización y de la gestión discursiva. Semánticamente, quedan fuera del contenido proposicional sobre el que actúan. Sin embargo, todavía se adscriben al territorio de la sintaxis oracional ${ }^{26}$. En cambio, las fórmulas en construcción parentética se ajustan mejor al prototipo de marcador: presentan una configuración marginal y extrapredicativa ${ }^{27}$ que les permite actuar, semántica y discursivamente, sobre el conjunto de un enunciado o sobre una parte de él.

\section{Conclusiones}

Volviendo la mirada hacia atrás, si consideramos de manera conjunta las propiedades que se recogen en la tabla 2 (§ 5.5.) , y teniendo en cuenta las funciones discursivas analizada a lo largo de los apartados 3 y 4, la trayectoria que va de izquierda a derecha nos permite definir un recorrido gradual que describe el paso desde aquellas formas que más se aproximan al prototipo de marcador del discurso a aquellas otras que, al adscribirse al dominio de la sintaxis oracional, más se apartan de él, aun cuando sigan teniendo un importante papel en la construcción del discurso.

25 Alvarado Ortega (2010: 27), al ocuparse de las fórmulas rutinarias, define la fijación formal como "estabilidad en el orden de sus componentes, en sus categorías gramaticales, en su inventario y en su transformatividad". Las fórmulas rutinarias actúan como un todo uniforme que puede tener variantes, aunque sin cambio de significado.

26 Sin embargo, según Llorente Arcocha (1996: 283), esto no es ningún problema para poder categorizar una construcción léxica como operador discursivo. Sí son en cambio requisitos imprescindibles el que se utilice para cumplir una tarea relacionada con la organización del discurso y el que se sienta ya como un procedimiento asociado convencionalmente a ese tipo de función.

27 Llorente Arcocha (1996: 280-289) insiste que ciertas propiedades formales como la movilidad, el carácter periférico o incidental, la independencia entonativa, la autonomía sintáctica... no son condiciones ni necesarias ni suficientes para incluir un elemento dentro de la categoría funcional de los operadores discursivos. Son, eso sí, propiedades típicas de los componentes centrales de la categoría. 
Debe quedar claro que incluso en el caso de las formas situadas a la izquierda no se ha alcanzado una gramaticalización plena y que solo se pueden caracterizar como “marcadores del discurso” si aceptamos el tipo de categorización no discreta que se defiende desde la teoría de los prototipos (Lakoff 1987, Kleiber 1990, Cuenca y Hilferty 1999). En realidad, las formas situadas a la izquierda de la tabla presentan rasgos que los aproximan a los procedimientos gramaticalizados y a los que se basan en el léxico. Se encuentran, por tanto, en un punto intermedio dentro del continuum léxico-gramática ${ }^{28}$. Aunque no están plenamente gramaticalizados, se sienten ya como procedimientos convencionales ligados al cumplimiento de una función pragmáticodiscursiva y, desde este planteamiento, pueden considerarse representantes, aunque periféricos, de la categoría.

\section{OBRAS CITADAS}

Aijmer, K., A. Foolen y A-M. Simon-Vandenbergen. 2006. "Pragmatic markers in translation: A methodological proposal". Ed. K. Fischer. Approaches to discourse particles. Oxford: Elsevier. 101-114.

Alvarado Ortega, M. B. 2010. Las fórmulas rutinarias del español: teoría y aplicaciones. Frankfurt am Main: Peter Lang.

Alvarado Ortega, M. B. y L. Ruiz Gurillo. 2011. "Un acercamiento fraseológico a desde luego". RILCE 27.2: 305-320

Anscombre, J.-Cl. y O. Ducrot. 1977. “Deux mais en français?”. Lingua 43: 23-40.

Anscombre, J.-Cl. y O. Ducrot. 1988. L'argumentation dans la langue. Liège: Pierre Mardaga Éditeur.

Blakemore, D. 1992. Understanding utterances. An introduction to Pragmatics. Oxford: Blackwell.

Bosque, I. 1980. Sobre la negación. Madrid: Cátedra.

Bosque, I. 1990. "Las bases gramaticales de la alternancia modal. Repaso y balance”. Ed. I. Bosque. Indicativo y subjuntivo. Madrid: Taurus. 13-65.

Brinton, L. J. 1996. Pragmatic markers in English. Grammaticalization and discourse functions. Berlin: Mouton/De Gruyter.

Brinton, L. J. 2007. “The development of I mean: Implications for Historical Pragmatics”. Eds. S. Fitzmaurice e I. Taavitsainen. Methods in Historical Pragmatics. Berlin: Mouton de Gruyter. 37-80.

Briz, A. y Grupo Val.Es.Co. 2003. "Un sistema de unidades para el estudio del lenguaje coloquial”. Oralia 6: 7-61.

Company Company, C. 2004. “¿Gramaticalización o desgramaticalización? Reanálisis y subjetivización de verbos como marcadores discursivos en la historia del español”. RFE LXXXIV.1: 29-66.

Confais, J-P. 1990. Temps, mode, aspect. Les approaches des morphèmes verbaux et leurs problèmes à l'exemple du français et de l'allemand. Toulouse: Presses Universitaires du Mirail.

28 La gramática sistémico-funcional de M.A.K. Halliday ha propuesto el término "lexico-grammar" como reconocimiento del hecho de que entre léxico y gramática no hay una separación discreta, sino un paso gradual. Llorente Arcocha insiste en la posibilidad de tener marcadores del discurso que se encuentren en esa zona intermedia: “Ciertos operadores discursivos (...) son miembros de una clase formal de unidades que está a medio camino entre la sintaxis y el léxico: precisamente aquéllos que definen parcialmente su valor gracias a sus contenidos léxicos y que, al mismo tiempo, tienen una organización interna parcial o totalmente definida por reglas sintácticas" (1996: 331-332). 
Cuenca, Ma. J. 2001. "Los conectores parentéticos como categoría gramatical”. Lingüística Española Actual XXIII.2: 211-235.

Cuenca, M. J. y J. Hilferty. 1999. Introducción a la lingüística cognitiva. Barcelona: Ariel.

Ducrot, O. 1986. El decir y lo dicho. Polifonía de la enunciación. Barcelona: Paidós.

Ducrot, O. 1990. Polifonía y argumentación. Conferencias del seminario de argumentación y análisis del discurso. Cali: Universidad del Valle.

Fraser, B. 1999. “An approach to discourse markers”. Journal of Pragmatics 14: 383-395.

Fuentes Rodríguez, C. 1999. La organización informativa del texto. Madrid: Arco/Libros.

Fuentes Rodríguez, C. 2009. Diccionario de conectores y operadores del español. Madrid: Arco/Libros.

Grande Alija, F. J. 2002. Aproximación a las modalidades enunciativas. León: Universidad de León.

Gutiérrez Ordóñez. S. 1997. Temas, remas, focos, tópicos y comentarios. Madrid: Arco/Libros.

Hopper, P. J. y E. Traugott. 1993. Grammaticalization. Cambridge: Cambridge University Press.

Kleiber, G. 1990. La sémantique du prototype. Catégories et sens lexical. París: PUF.

Lakoff, G. 1987. Women, fire and dangerous things. What categories reveal about the mind. Chicago: University of Chicago Press.

Landone, E. 2009. Los marcadores del discurso y cortesía verbal en español. Bern: Peter Lang.

Leonetti, M y M. V. Escandell, M. V. 2004. “Semántica conceptual / semántica procedimental”. Ed. M. Villayandre Llamazares. Actas del V Congreso de Lingüística General. Vol. 2. Madrid: Arco/Libros. 3 vols. 1727-1738.

Llorente Arcocha, M. ${ }^{a}$ T. 1996. Organizadores de la conversación. Operadores discursivos en español. Salamanca: Publicaciones de la Universidad Pontificia de Salamanca.

Martín Zorraquino, Ma. A. y J. Portolés. 1999. “Los marcadores del discurso”. Eds. I. Bosque y V. Demonte. Gramática descriptiva del español. Entre oración y discurso. Morfología. Vol. 3. Madrid: Espasa-Calpe. 3 vols. 4051-4213.

Montolíu Durán, E. 1998. “La teoría de la relevancia y el estudio de los marcadores”. Eds M. A. Zorraquino y E. Montolíu Durán. Los marcadores del discurso. Teoría y análisis. Madrid: Arco/Libros. 93-119.

Morgan, J. L. 1978. “Two types of convention in indirect speech acts”. Ed. P. Cole. Syntax and Semantics 9. Pragmatics. New York: Academic Press. 261-280.

Pons Bordería, S. 1998. Conexión y conectores. Estudio de su relación en el registro informal de la lengua. Anejo XXVII de la revista Cuadernos de filología. Valencia: Universidad de Valencia.

Pons Bordería, S. 2000. “Los conectores”. Eds. A. Briz y Grupo Val.Es.Co. ¿Cómo se comenta un texto coloquial? Barcelona: Ariel. 193-220.

Portolés, J. 1998. Marcadores del discurso. Barcelona: Ariel.

Rodríguez Rosique, S. 2008. Pragmática y Gramática. Condicionales concesivas en español. Frankfurt am Maim: Peter Lang.

Santos Río, L. 2003. Diccionario de partículas. Salamanca: Luso-Española de Ediciones.

Sperber, D. y D. Wilson. 1994. La relevancia. Comunicación y procesos cognitivos. Madrid: Visor.

Traugott, E. C. 1995a. "Subjectification in grammaticalization". Eds. S. Wright y D. Stein. Subjectivity and Subjectivization. Cambridge: Cambridge University Press. 31-54.

Traugott, E. C. 1995b. "The role of grammaticalization in the development of discourse markers”, comunicación presentada en el ICHL XII (Manchester). Disponible en: http://www.stanford.edu/ traugott/papers/discourse.pdf

Verschueren, J. 2002. Para entender la pragmática. Madrid: Gredos.

Wilson, D. y D. Sperber. 1993. "Linguistic form and relevance”, Lingua 90: 1-25.

Zuluaga, A. 1980. Introducción al estudio de las expresiones fijas. Frankfurt am Main: Lang. 


\section{Procedencia de los ejemplos}

Briz, A. coord. 1995. La conversación coloquial (Materiales para su estudio). Anejo XVI de Cuadernos de Filología. Valencia: Universitat de València.

García Sánchez, J. 2003. Dios se ha ido. Barcelona: Planeta.

Real ACADEmia Española. Corpus de referencia del español actual (CREA). (http://www.rae). Ruiz Zafón, C. 2008. El juego del ángel. Barcelona: Editorial Planeta.

Steel, B. 1976. A Manual of Colloquial Spanish. Madrid: Sociedad General Española de Librería.

Valcárcel, D. 2008. “Honor al Chikilicuatre”. Diario ABC. 22-5-2008: 1 